\title{
Association between triglycerides and cardiovascular events in primary populations: a meta-regression analysis and synthesis of evidence
}

This article was published in the following Dove Press journal:

Vascular Health and Risk Management

30 October 2013

Number of times this article has been viewed

\author{
Melissa E Stauffer \\ Lauren Weisenfluh \\ Alan Morrison \\ SCRIBCO, Effort, PA, USA
}

Correspondence: Melissa E Stauffer clo SCRIBCO, PO Box 580, Effort, PA 18330, USA

Tel + I 2623945258

Fax + I 2627254044

Email melstauff@charter.net
Background: Triglyceride levels were found to be independently predictive of the development of primary coronary heart disease in epidemiologic studies. The objective of this study was to determine whether triglyceride levels were predictive of cardiovascular events in randomized controlled trials (RCTs) of lipid-modifying drugs.

Methods: We performed a systematic review and meta-regression analysis of 40 RCTs of lipid-modifying drugs with cardiovascular events as an outcome. The log of the rate ratio of cardiovascular events (eg, coronary death or myocardial infarction) was plotted against the proportional difference between treatment and control groups in triglyceride and other lipid levels (high density lipoprotein cholesterol [HDL-C], low density lipoprotein cholesterol [LDL-C], and total cholesterol) for all trials and for trials of primary and secondary prevention populations. Linear regression was used to determine the statistical significance of the relationship between lipid values and cardiovascular events.

Results: The proportional difference in triglyceride levels was predictive of cardiovascular events in all trials $(P=0.005$ for the slope of the regression line; $\mathrm{N}=40)$ and in primary prevention trials $(P=0.010 ; \mathrm{N}=11)$, but not in secondary prevention trials $(P=0.114 ; \mathrm{N}=25)$. The proportional difference in HDL-C was not predictive of cardiovascular events in all trials $(P=0.822$; $\mathrm{N}=40)$, or in trials of primary $(P=0.223 ; \mathrm{N}=11)$ or secondary $(P=0.487 ; \mathrm{N}=25)$ prevention. LDL-C levels were predictive of cardiovascular events in both primary $(P=0.002 ; \mathrm{N}=11)$ and secondary $(P<0.001 ; \mathrm{N}=25)$ populations.

Conclusions: Changes in triglyceride levels were predictive of cardiovascular events in RCTs. This relationship was significant in primary prevention populations but not in secondary prevention populations.

Keywords: cardiovascular diseases, triglycerides, cholesterol, risk factors

\section{Introduction}

Dyslipidemia is a risk factor for cardiovascular disease. An elevated level of lowdensity lipoprotein cholesterol (LDL-C) is the most critical lipid risk factor. ${ }^{1,2}$ In patients who attain LDL-C target levels, there remains a residual risk of cardiovascular events, which might be associated with elevated levels of triglycerides or low levels of high-density lipoprotein cholesterol (HDL-C). ${ }^{3}$

Guidelines for coronary heart disease (CHD) risk assessment focus on either total cholesterol or LDL-C and are inconsistent in their recommendations regarding triglycerides and HDL-C. ${ }^{2,4,5}$ The US Adult Treatment Panel III guideline identifies LDL-C as the primary target for lipid-lowering therapy but includes low HDL-C (but not elevated triglycerides) as a risk factor. ${ }^{2}$ The UK guideline recognizes triglycerides as an ancillary 
risk factor, ${ }^{4}$ while the European guideline recognizes both triglycerides and HDL-C as risk factors. ${ }^{5}$ European and UK guidelines include HDL-C in risk assessment algorithms in the form of the total cholesterol (TC):HDL-C ratio. ${ }^{4,5}$ None of these guidelines specifies levels of triglycerides or HDL-C as treatment targets.

Several independent lines of evidence are available to address the question of the relationship between CHD and elevated levels of triglycerides and low levels of HDL-C: epidemiologic, genetic, and clinical trials of lipid-modifying drugs. ${ }^{6}$ Large observational (cohort) studies of the general population indicate that both elevated triglycerides and reduced plasma levels of HDL-C are associated with increased cardiovascular risk. ${ }^{6}$ Genetic evidence suggests a causal association between triglycerides and CHD, whereas data for gene variants associated with isolated changes in plasma HDL-C levels are conflicting. ${ }^{6}$ Clinical trials of drugs targeting triglycerides and HDL-C - niacin, ${ }^{7,8}$ resins (bile acid sequestrants), ${ }^{9,10}$ and fibrates ${ }^{11}$ - indicate that these agents can reduce the risk of coronary events.

There is another independent line of evidence: metaregression analysis. Briel et al used this approach to measure the association between changes in HDL-C levels and coronary events. ${ }^{12}$ These authors concluded that increasing circulating HDL-C levels did not reduce the risk of coronary events. ${ }^{12}$ Meta-regression analysis has also been used to measure the association between changes in plasma triglyceride levels and stroke and carotid intima-media thickness, which is a measure of sub-clinical atherosclerosis. ${ }^{13}$ No significant associations were observed. There is, however, to our knowledge no published meta-regression analysis of the relationship between triglycerides and coronary events.

The objective of this study was thus to use metaregression analysis of drug trial data to measure the association between the change in plasma triglyceride levels and coronary events. We discuss the results in the context of the other lines of evidence of the relationship between CHD and triglycerides and HDL-C.

\section{Methods}

\section{Literature searches}

Clinical trials were identified from selected systematic reviews and meta-analyses published through the year 2007. ${ }^{14-17}$ PubMed was subsequently searched with the string "Randomized Controlled Trial" [All Fields] AND "antilipemic agents" [All Fields] AND "cardiovascular event" [All Fields] AND (Clinical Trial [ptyp] AND English [lang]) over the period of January 1, 2007 to January 24, 2012 to identify more recent trials.

\section{Study selection and data abstraction}

Clinical trials were included in the analysis if they were reports of parallel-group, randomized, controlled trials of lipid-modifying drugs, presented data on triglyceride levels, had one or more cardiovascular events as an outcome, were written in English, and were published in the peer-reviewed literature. The control treatment could be placebo, diet, usual care, or active treatment with a different drug or the same drug at a different dose. Active treatments included statins, fibrates, bile acid sequestrants, cholesterol absorption inhibitors, and nicotinic acids. Cardiovascular events were reported as composite endpoints, most commonly coronary death or myocardial infarction, though stroke, angina, and revascularization also appeared as outcomes in some studies. Studies were excluded if lipid data or cardiovascular outcomes were inadequately reported or if they presented results from a subgroup of a primary trial.

Data from the selected trials were abstracted into an Access database consisting of three relational data sets: information about the trial, information about the specific article, and the study results. Fields for the trial data set were the trial name and the trial acronym. Fields for the specific article were the citation, an abbreviation of the citation (first author and publication year), a description of the patients (CHD, diabetes, hypercholesterolemia, etc), CHD classification (primary or secondary prevention), the trial duration in years, the numbers of men and women, the outcome type (cardiovascular events, CHD events, atherosclerosis, or combinations thereof), and the drug class of the active treatment. Primary prevention trials were defined as those in which patients had had no prior cardiovascular events; a history of CHD in $<15 \%$ of subjects was allowed (in the case of the Antihypertensive and Lipid-Lowering Treatment to Prevent Heart Attack Trial [ALLHAT-LLT]), ${ }^{18}$ as was a history of stroke (the Stroke Prevention by Aggressive Reduction in Cholesterol Levels trial [SPARCL]) ${ }^{19}$ or hypercholesterolemia (the Ezetimibe and Simvastatin in Hypercholesterolemia Enhances Atherosclerosis Regression trial [ENHANCE]), ${ }^{20}$ as long as there had been no cardiovascular events. Secondary prevention trials were studies in which patients had experienced a cardiovascular event or were at increased risk of an event due to a cardiovascular risk equivalent (eg, diabetes in the Collaborative Atorvastatin Diabetes Study [CARDS], ${ }^{21}$ the Fenofibrate Intervention and Event Lowering in Diabetes trial [FIELD], ${ }^{22}$ and the 
Outcome Reduction with an Initial Glargine Intervention trial [ORIGIN]). ${ }^{23}$ Trials were classified as mixed primary and secondary prevention if a proportion of subjects $>15 \%$ had a history of cardiovascular events (the Action to Control Cardiovascular Risk in Diabetes trial [ACCORD],${ }^{24}$ and the Heart Protection Study [HPS]), ${ }^{25}$ diabetes (the Hokuriku Lipid Coronary Heart Disease Study-Pravastatin Atherosclerosis Trial [Holicos-PAT]), ${ }^{26}$ or vascular disease (the Prospective Study of Pravastatin in the Elderly at Risk [PROSPER], ${ }^{27}$ Holicos-PAT). ${ }^{26}$ The results data set included the names of the active and control treatment arms, the number of subjects in the treatment arm, the type of cardiovascular event, the number of events, and lipid values (triglyceride, HDL-C, total cholesterol, and LDL-C) at the study endpoint or midpoint or, alternatively, as the on-study average.

\section{Statistical analysis}

For each trial, the cardiovascular event rate (number of events divided by total person-years) in the treatment arm was divided by the rate in the control arm to obtain the rate ratio. The logarithm of the rate ratio was plotted against the proportional difference in triglyceride levels, calculated as:

$$
\left(\mathrm{TG}_{t}-\mathrm{TG}_{c}\right) / \mathrm{TG}_{c},
$$

where TG is triglycerides and subscripts $t$ and $c$ represent the treatment and control groups, respectively. Proportional differences in the other lipid values (HDL-C, total cholesterol, and LDL-C) were calculated in the same way. Linear regression, performed in Comprehensive Meta-Analysis v. 2.2.021 (Biostat Inc., Englewood, NJ, USA), was used to assess the effect of lipid levels on the rate ratio, first in all patients and then in patients with and without prior cardiovascular events/conditions that is, the secondary and primary prevention populations, respectively. In order to investigate potential confounding with other lipid variables, the analysis was repeated in subgroups of trials stratified by HDL-C, total cholesterol, and LDL-C levels above and below the median values. The $P$-value for the slope of the regression line was used to determine whether the proportional difference in the lipid values was predictive of a difference in the rate of cardiovascular events between the treatment and control groups. A $P$-value $<0.05$ was considered statistically significant.

\section{Results}

\section{Studies included in the analysis}

Forty studies met the inclusion criteria, with a total enrollment of 200,593 patients (Supplementary materials
A

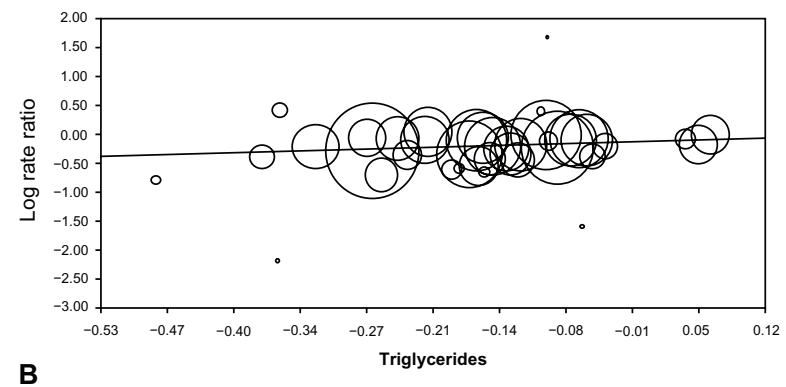

B

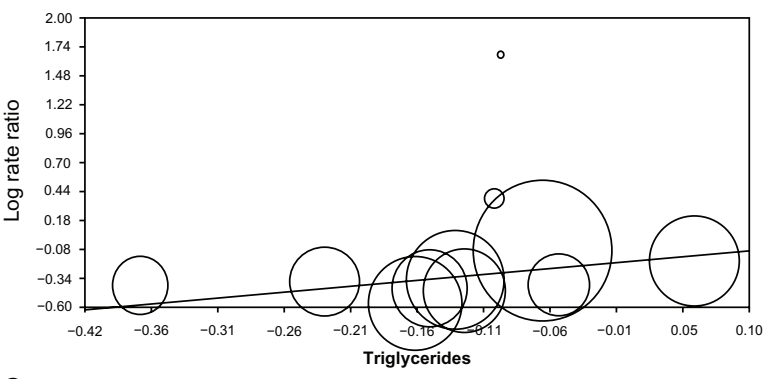

C

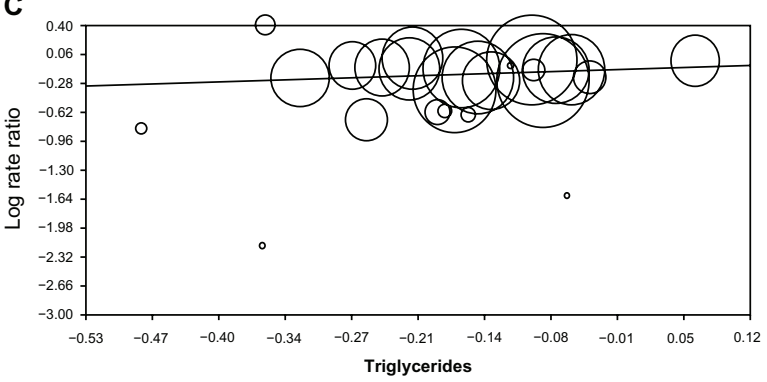

Figure I Regression of triglycerides on the log of the rate ratio for (A) all trials, (B) primary prevention trials, and (C) secondary prevention trials. Each panel shows the output from regression analysis in Comprehensive Meta-Analysis.

Notes: (A) 40 trials, slope $=0.488, P=0.005$; (B) II trials, slope $=1.031$, $P=0.010$; (C) 25 trials, slope $=0.373, P=0.114$.

Table S1). Eleven trials were studies of primary prevention of a cardiovascular event ${ }^{9,18-20,28-34}$ and 25 were studies of secondary prevention; ${ }^{10,21-23,35-55}$ four trials included both types of prevention. ${ }^{24-27}$

\section{Triglycerides and cardiovascular events in primary and secondary populations}

Figure 1 shows the regression plots for triglycerides versus cardiovascular events. Based on the $P$-value of the slope of the regression line $(P=0.005)$, triglycerides (ie, the proportional difference) were predictive of cardiovascular events for all trials (Table 1). Triglycerides were significantly predictive of cardiovascular events in the 11 trials of primary prevention ( $P=0.010$; Table 1$)$, but not in the 25 trials of secondary prevention $(P=0.114$; Table 1$)$.

Table 1 presents the results of additional regression analyses using HDL-C, total cholesterol, and LDL-C as independent variables, which show that HDL-C was not predictive 
Table I Statistics for the regression analyses of lipid values versus cardiovascular events ${ }^{\mathrm{a}}$

\begin{tabular}{|c|c|c|c|c|c|c|c|c|}
\hline & \multicolumn{2}{|c|}{ Triglycerides } & \multicolumn{2}{|l|}{ HDL-C } & \multicolumn{2}{|c|}{ Total cholesterol $^{\mathrm{b}}$} & \multicolumn{2}{|c|}{ LDL-C } \\
\hline & Slope & $P$-value & Slope & $P$-value & Slope & $P$-value & Slope & $P$-value \\
\hline All studies $(\mathrm{N}=40)$ & 0.488 & 0.005 & 0.085 & 0.822 & 1.030 & $<0.00 \mathrm{I}$ & 0.624 & $<0.001$ \\
\hline \multicolumn{9}{|l|}{ Population $(\mathrm{N}=36)^{c}$} \\
\hline Primary prevention $(\mathrm{N}=\mathrm{I} \mathrm{I})$ & 1.031 & 0.010 & 2.251 & 0.223 & 1.232 & 0.044 & 0.932 & 0.002 \\
\hline Secondary prevention $(\mathrm{N}=25)$ & 0.373 & 0.114 & -0.288 & 0.487 & 1.264 & $<0.001$ & 0.507 & $<0.001$ \\
\hline \multicolumn{9}{|l|}{ HDL-C level $(\mathrm{N}=40)$} \\
\hline Low $(\mathrm{N}=20)$ & 0.605 & 0.013 & 0.127 & 0.773 & 1.294 & $<0.00$ I & 0.539 & $<0.001$ \\
\hline High $(\mathrm{N}=20)$ & 0.624 & 0.018 & 0.719 & 0.367 & 0.602 & 0.041 & 0.776 & $<0.001$ \\
\hline \multicolumn{9}{|l|}{ LDL-C level $(\mathrm{N}=40)$} \\
\hline Low $(\mathrm{N}=20)$ & 0.765 & 0.010 & 0.252 & 0.625 & 0.952 & $<0.001$ & 0.585 & $<0.001$ \\
\hline High $(\mathrm{N}=20)$ & 0.352 & 0.136 & -0.460 & 0.497 & 1.392 & $<0.00 \mathrm{I}$ & 0.888 & $<0.001$ \\
\hline \multicolumn{9}{|l|}{ Total cholesterol level $(\mathrm{N}=38)^{\mathrm{b}}$} \\
\hline Low $(N=19)$ & 0.765 & 0.005 & -1.575 & 0.023 & 0.844 & $<0.00 \mathrm{I}$ & 0.594 & $<0.001$ \\
\hline High $(\mathrm{N}=19)$ & 0.456 & 0.107 & -0.455 & 0.502 & 1.475 & $<\mathbf{0 . 0 0 1}$ & 1.026 & $<\mathbf{0 . 0 0 1}$ \\
\hline
\end{tabular}

Notes: aBold font indicates statistical significance at $P<0.05$; bJUPITER and AIM-HIGH, which did not report total cholesterol, were omitted from analyses of total cholesterol; 'the analyses omitted the four trials with mixed primary and secondary populations.

Abbreviations: AIM-HIGH, Atherothrombosis Intervention in Metabolic syndrome with low HDL/High triglycerides: Impact on Global Health outcomes; HDL-C, high-density lipoprotein cholesterol; JUPITER, Justification for the Use of Statins in Prevention: an Intervention Trial Evaluating Rosuvastatin; LDL-C, low-density lipoprotein cholesterol.

of cardiovascular events in either primary $(P=0.223)$ or secondary $(P=0.487)$ populations. Total cholesterol and LDL-C were predictive of cardiovascular events in both primary and secondary populations.

\section{Stratification by HDL-C, LDL-C, and total cholesterol}

To partially adjust for the inverse correlation between serum HDL-C and triglyceride levels, we stratified the analysis by on-study HDL-C levels of the active treatment groups. The median value of HDL-C across all the trials was $46.1 \mathrm{mg} / \mathrm{dL}$, with a range of 32.7 to $60.3 \mathrm{mg} / \mathrm{dL}$. Triglycerides were predictive of cardiovascular events in trials with HDL-C below $(P=0.013)$ and above $(P=0.018)$ the median (Table 1$)$. Total cholesterol and LDL-C were also predictive of cardiovascular events in both sets of trials (Table 1).

The median values of LDL-C and total cholesterol in the active treatment groups were $100.2 \mathrm{mg} / \mathrm{dL}$ (range 55-181.7) and $172.2 \mathrm{mg} / \mathrm{dL}$ (range 135-257.1), respectively. When the trials were stratified by level of LDL-C (Table 1), triglycerides were predictive of cardiovascular events in the group below the median $(P=0.010)$, but not in the group above the median $(P=0.136)$. Similarly, triglycerides predicted cardiovascular events in trials below the median total cholesterol $(P=0.005)$, but not in those with total cholesterol above the median $(P=0.107)$.

\section{Discussion}

The issue of whether triglycerides are significantly associated with CHD in primary but not secondary populations can be addressed by evidence from meta-regression analysis, cohort studies, and clinical trials of lipid-modifying drugs. In the current meta-regression analysis, triglyceride levels were significantly predictive of cardiovascular events in primary but not secondary patient populations. Similarly, in a systematic review of epidemiologic cohort studies, an independent association between elevated triglycerides and risk of CHD was statistically significant in 16 of 30 populations without pre-existing CHD, whereas triglycerides were not independently associated with CHD in any of eight cohorts of patients with pre-existing CHD or diabetes mellitus. ${ }^{56}$

Clinical trials of lipid-modifying drugs targeting triglycerides (fibrates, niacin, and resins) and measuring CHD outcomes have been conducted mostly in secondary populations. In the current analysis only two of these trials were conducted in primary populations and eight were conducted in secondary populations. The two trials conducted in primary populations were the Helsinki Heart Study (HHS) and the Lipid Research Clinics Coronary Primary Prevention Trial (LRCCPPT) ${ }^{9,30}$ In HHS, gemfibrozil significantly reduced the risk of CHD $(P=0.02)$. In the LRC-CPPT trial of cholestyramine, the $P$-value was 0.08 . The pooled random effects rate ratio for these two trials was $0.78(0.65-0.93), P=0.006$. Of the eight trials conducted in secondary populations (trials of cholestyramine, ${ }^{10}$ gemfibrozil, ${ }^{47,55}$ bezafibrate, ${ }^{40,41}$ fenofibrate, ${ }^{22}$ and niacin in combination with either gemfibrozil and cholestyramine ${ }^{36}$ or simvastatin), ${ }^{37}$ in only one (the Veterans Affairs High-density Lipoprotein Cholesterol Intervention Trial [VA-HIT]) was there a statistically significant effect on coronary events $(P=0.01) .{ }^{55}$ The $P$-values in the other seven trials ranged from 
0.07 to 0.93 . The pooled random effects statistic for all eight trials trended towards but did not reach significance: rate ratio 0.91 (0.80-1.03), $P=0.15$.

The consensus of these different lines of evidence is that the relationship between triglycerides and CHD is manifested in primary patient populations but not in secondary populations. Part of the explanation of this may be that triglycerides remain a risk factor in secondary populations - the $P$-value of 0.114 represents a trend - but that the magnitude of the risk is small in relation to the total risk of coronary events. This can be illustrated as follows. The median risk of CHD events in the placebo/control groups of clinical trials of about 5 years duration was $4.6 \%$ in primary populations ${ }^{9,19,30,31,33,34}$ and $15.5 \%$ in secondary populations..$^{22,35,38,41,42,49}$ In the same set of trials, the median absolute reduction in the risk of coronary events resulting from treatment with the triglyceridemodifying drugs gemfibrozil, cholestyramine, bezafibrate, or fenofibrate was $1.4 \% .{ }^{9,22,30,41}$ This absolute risk reduction represents a relative risk reduction of $27.9 \%$ in the primary trials but only $8.4 \%$ in the secondary trials. This also explains the failures of clinical trials of drugs targeting triglycerides to achieve a statistically significant result in secondary populations. These trials were powered to detect a relative risk reduction of $20 \%-25 \%,{ }^{22,41}$ not an effect as small as $8 \%$.

Plasma triglycerides and HDL-C are related metabolically and mechanistically in the pathophysiology of atherosclerosis, making it difficult to distinguish their effects on cardiovascular disease. ${ }^{6}$ Triglycerides are one of many components of HDL particles, and enrichment of those particles with triglycerides may lead to dysfunctional metabolism that results in atherogenesis. ${ }^{57}$ Plasma triglyceride and HDL-C levels are typically weakly-to-moderately anti-correlated in population based cohort studies. ${ }^{56}$ This seesaw relationship is seen in the effects of lipid-modifying drugs, which concomitantly increase HDL-C and decrease triglyceride levels. ${ }^{7,16,58-60}$ Mutations in genes encoding lipoprotein lipase and cholesteryl ester transfer protein have inverse effects on plasma levels of triglycerides and HDL-C, with corresponding effects on the risk of CHD. ${ }^{61-65}$

Genetic evidence relating triglycerides to $\mathrm{CHD}$ comes from the $-1131 \mathrm{~T}>\mathrm{C}$ allele of APOA5, which encodes apolipoprotein A-V, a protein associated with triglyceride-rich very LDL (VLDL). First, $-1131 \mathrm{~T}>\mathrm{C}$ is unrelated to plasma levels of LDL-C and comparatively moderately related to levels of HDL-C. ${ }^{66}$ Second, $-1131 \mathrm{~T}>\mathrm{C}$ is strongly related to triglyceride concentration in a dose-dependent manner. ${ }^{66}$ Third, $-1131 \mathrm{~T}>\mathrm{C}$ is related to risk of CHD in an analogous dose-dependent manner. ${ }^{66}$ These findings are consistent with a causal role for triglyceride-mediated pathways in CHD. ${ }^{66}$ Cohort studies are consistent with an association between elevated levels of plasma triglycerides and subsequent cardiovascular events in primary populations. ${ }^{56}$ In meta-regression analysis of clinical drug trials (the current analysis), changes in triglyceride levels were predictive of cardiovascular events in primary prevention populations.

For HDL-C, the pertinent genetic evidence comes from alleles of $A B C A 1$, a gene encoding adenosine triphosphatebinding cassette transporter A1. Loss-of-function mutations in $A B C A 1$ decrease serum HDL-C but do not change levels of triglycerides or LDL-C; there is no associated risk of CHD. ${ }^{67}$ This argues against HDL-C having a causal relationship with $\mathrm{CHD}{ }^{67}$ In cohort studies, low HDL-C levels were predictive of coronary events (as opposed to coronary death) in 10 of 20 analyses of patients without pre-existing CHD. ${ }^{56} \mathrm{~A}$ meta-regression analysis reported by Briel et al showed no association between treatment-induced changes in HDL-C and risk of CHD. ${ }^{12}$ The current meta-regression analysis corroborates this result.

In summary, both genetic evidence and meta-regression analysis point to a relationship between circulating triglyceride levels and CHD and the absence of a relationship between HDL-C and CHD. The evidence from population-based cohort studies is equivocal but consistent with a relationship between CHD and triglycerides and/or HDL-C. Meta-regression analysis of clinical trial data constitutes observational evidence of associations between lipid levels and subsequent cardiovascular events. We addressed the possibility of systematic error due to confounding between lipid variables in stratified analyses. The results of these analyses indicate that there was no confounding with low HDL-C or high LDL-C or total cholesterol levels. The association between triglycerides and CHD events, however, was statistically significant in the low LDL-C and total cholesterol strata.

In cohort studies, the potential for confounding has been addressed by multivariable modeling. However, these analyses varied in the choice of type of model, in the lipid and non-lipid variables included, and in the structure of those variables. ${ }^{56}$ The subjectivity in choosing these model features introduces the potential for systematic error, and there is evidence of confounding between triglycerides and HDL-C. ${ }^{56}$ The pooling of individual patient data of multiple population-based cohort studies, as in the Emerging Risk Factor Collaboration analysis, reduces random error by increasing the sample size but does not remove the potential for systematic error ${ }^{68}$ Metaanalysis of cohort studies - in which cohorts of patients rather than individual patients are the unit of pooling - produces statistically heterogeneous data sets. ${ }^{69}$ The alternative approach 
is the systematic tallying of cohort studies according to whether they recorded a statistically significant relationship between triglyceride levels and coronary events. ${ }^{56}$

In conclusion, meta-regression analysis of clinical trial data agrees with genetic evidence and analyses of cohort studies, indicating that plasma triglyceride levels are predictive of the risk of CHD. Furthermore, both meta-regression and systematic review of cohort studies suggest that this risk is manifest in primary but not secondary populations. This argues that triglycerides might be considered as a factor in risk assessment algorithms in primary populations, and that drugs targeting triglyceride levels are not a priority in secondary populations. Genetic evidence and meta-regression analysis argue against a causal relationship between HDL-C and $\mathrm{CHD}$.

\section{Acknowledgment}

Funding for this study was provided by SCRIBCO.

\section{Disclosure}

All authors received remuneration from SCRIBCO to perform the work described in this manuscript.

\section{References}

1. Baigent C, Keech A, Kearney PM, et al. Cholesterol Treatment Trialists' (CTT) Collaborators. Efficacy and safety of cholesterol-lowering treatment: prospective meta-analysis of data from 90,056 participants in 14 randomised trials of statins. Lancet. 2005;366(9493):1267-1278.

2. Grundy SM, Cleeman JI, Merz CN, et al; National Heart, Lung, and Blood Institute; American College of Cardiology Foundation; American Heart Association. Implications of recent clinical trials for the National Cholesterol Education Program Adult Treatment Panel III guidelines. Circulation. 2004;110(2):227-239.

3. Robinson JG. Management of complex lipid abnormalities with a fixed dose combination of simvastatin and extended release niacin. Vasc Health Risk Manag. 2009;5(1):31-43.

4. British Cardiac Society; British Hypertension Society; Diabetes UK; HEART UK; Primary Care Cardiovascular Society; Stroke Association. JBS 2: Joint British Societies' guidelines on prevention of cardiovascular disease in clinical practice. Heart. 2005; 91 Suppl 5:v1-v52.

5. Graham I, Atar D, Borch-Johnsen K, et al; European Society of Cardiology (ESC) Committee for Practice Guidelines (CPG). European guidelines on cardiovascular disease prevention in clinical practice: executive summary: Fourth Joint Task Force of the European Society of Cardiology and Other Societies on Cardiovascular Disease Prevention in Clinical Practice (Constituted by representatives of nine societies and by invited experts). Eur Heart J. 2007;28(19): 2375-2414.

6. Chapman MJ, Ginsberg HN, Amarenco P, et al; European Atherosclerosis Society Consensus Panel. Triglyceride-rich lipoproteins and highdensity lipoprotein cholesterol in patients at high risk of cardiovascular disease: evidence and guidance for management. Eur Heart J. 2011;32(11):1345-1361.

7. Birjmohun RS, Hutten BA, Kastelein JJ, Stroes ES. Efficacy and safety of high-density lipoprotein cholesterol-increasing compounds: a metaanalysis of randomized controlled trials. J Am Coll Cardiol. 2005;45(2): 185-197.
8. Bruckert E, Labreuche J, Amarenco P. Meta-analysis of the effect of nicotinic acid alone or in combination on cardiovascular events and atherosclerosis. Atherosclerosis. 2010;210(2):353-361.

9. The Lipid Research Clinics Coronary Primary Prevention Trial results. I. Reduction in incidence of coronary heart disease. JAMA. 1984;251(3): 351-364.

10. Watts GF, Lewis B, Brunt JN, et al. Effects on coronary artery disease of lipid-lowering diet, or diet plus cholestyramine, in the St Thomas' Atherosclerosis Regression Study (STARS). Lancet. 1992;339(8793): 563-569.

11. Bruckert E, Labreuche J, Deplanque D, Touboul PJ, Amarenco P. Fibrates effect on cardiovascular risk is greater in patients with high triglyceride levels or atherogenic dyslipidemia profile: a systematic review and meta-analysis. J Cardiovasc Pharmacol. 2011;57(2):267-272.

12. Briel M, Ferreira-Gonzalez I, You JJ, et al. Association between change in high density lipoprotein cholesterol and cardiovascular disease morbidity and mortality: systematic review and meta-regression analysis. BMJ. 2009;338:b92.

13. Labreuche J, Deplanque D, Touboul PJ, Bruckert E, Amarenco P. Association between change in plasma triglyceride levels and risk of stroke and carotid atherosclerosis: systematic review and metaregression analysis. Atherosclerosis. 2010;212(1):9-15.

14. Brown BG, Stukovsky KH, Zhao XQ. Simultaneous low-density lipoprotein-C lowering and high-density lipoprotein-C elevation for optimum cardiovascular disease prevention with various drug classes, and their combinations: a meta-analysis of 23 randomized lipid trials. Curr Opin Lipidol. 2006;17(6):631-636.

15. Gould AL, Rossouw JE, Santanello NC, Heyse JF, Furberg CD. Cholesterol reduction yields clinical benefit: impact of statin trials. Circulation. 1998;97(10):946-952.

16. Edwards JE, Moore RA. Statins in hypercholesterolaemia: a dosespecific meta-analysis of lipid changes in randomised, double blind trials. BMC Fam Pract. 2003;4:18.

17. Gould AL, Davies GM, Alemao E, Yin DD, Cook JR. Cholesterol reduction yields clinical benefits: meta-analysis including recent trials. Clin Ther. 2007;29(5):778-794.

18. ALLHAT Officers and Coordinators for the ALLHAT Collaborative Research Group. The Antihypertensive and Lipid-Lowering Treatment to Prevent Heart Attack Trial. Major outcomes in moderately hypercholesterolemic, hypertensive patients randomized to pravastatin vs usual care: The Antihypertensive and Lipid-Lowering Treatment to Prevent Heart Attack Trial (ALLHAT-LLT). JAMA. 2002;288(23):2998-3007.

19. Amarenco P, Bogousslavsky J, Callahan A, et al; Stroke Prevention by Aggressive Reduction in Cholesterol Levels (SPARCL) Investigators. High-dose atorvastatin after stroke or transient ischemic attack. N Engl J Med. 2006;355(6):549-559.

20. Kastelein JJ, Akdim F, Stroes ES, et al; ENHANCE Investigators. Simvastatin with or without ezetimibe in familial hypercholesterolemia. N Engl J Med. 2008;358(14):1431-1443.

21. Colhoun HM, Betteridge DJ, Durrington PN, et al; CARDS investigators. Primary prevention of cardiovascular disease with atorvastatin in type 2 diabetes in the Collaborative Atorvastatin Diabetes Study (CARDS): multicentre randomised placebo-controlled trial. Lancet. 2004;364(9435):685-696.

22. Keech A, Simes RJ, Barter P, et al; FIELD study investigators. Effects of long-term fenofibrate therapy on cardiovascular events in 9795 people with type 2 diabetes mellitus (the FIELD study): randomised controlled trial. Lancet. 2005;366(9500):1849-1861.

23. Bosch J, Gerstein HC, Dagenais GR, et al; ORIGIN Trial Investigators. n-3 fatty acids and cardiovascular outcomes in patients with dysglycemia. N Engl J Med. 2012;367(4):309-318.

24. Ginsberg HN, Elam MB, Lovato LC, et al; ACCORD Study Group. Effects of combination lipid therapy in type 2 diabetes mellitus. $N$ Engl J Med. 2010;362(17):1563-1574.

25. Heart Protection Study Collaborative Group. MRC/BHF Heart Protection Study of cholesterol lowering with simvastatin in 20,536 high-risk individuals: a randomised placebo-controlled trial. Lancet. 2002;360(9326):7-22. 
26. Koizumi J, Shimizu M, Miyamoto S, Origasa H, Mabuchi H. Effect of pravastatin-induced LDL-cholesterol reduction on coronary heart disease and cerebrovascular disease in Japanese: Hokuriku lipid coronary heart disease study-pravastatin atherosclerosis trial (HolicosPAT). J Atheroscler Thromb. 2002;9(5):251-259.

27. Shepherd J, Blauw GJ, Murphy MB, et al. PROSPER study group. PROspective Study of Pravastatin in the Elderly at Risk. Pravastatin in elderly individuals at risk of vascular disease (PROSPER): a randomised controlled trial. Lancet. 2002;360(9346):1623-1630.

28. Downs JR, Clearfield M, Weis S, et al. Primary prevention of acute coronary events with lovastatin in men and women with average cholesterol levels: results of AFCAPS/TexCAPS. Air Force/Texas Coronary Atherosclerosis Prevention Study. JAMA. 1998;279(20): 1615-1622.

29. Sever PS, Dahlöf B, Poulter NR, et al; ASCOT investigators. Prevention of coronary and stroke events with atorvastatin in hypertensive patients who have average or lower-than-average cholesterol concentrations, in the Anglo-Scandinavian Cardiac Outcomes Trial - Lipid Lowering Arm (ASCOT-LLA): a multicentre randomised controlled trial. Lancet. 2003;361(9364):1149-1158.

30. Manninen V, Elo MO, Frick MH, et al. Lipid alterations and decline in the incidence of coronary heart disease in the Helsinki Heart Study. JAMA. 1988;260(5):641-651.

31. Ridker PM, Danielson E, Fonseca FA, et al; JUPITER Study Group. Rosuvastatin to prevent vascular events in men and women with elevated C-reactive protein. $N$ Engl J Med. 2008;359(21): 2195-2207.

32. Crouse JR, Raichlen JS, Riley WA, et al; METEOR Study Group Effect of rosuvastatin on progression of carotid intima-media thickness in low-risk individuals with subclinical atherosclerosis: the METEOR Trial. JAMA. 2007;297(12):1344-1353.

33. Nakamura H, Arakawa K, Itakura H, et al; MEGA Study Group. Primary prevention of cardiovascular disease with pravastatin in Japan (MEGA Study): a prospective randomised controlled trial. Lancet. 2006;368(9542):1155-1163.

34. Shepherd J, Cobbe SM, Ford I, et al. Prevention of coronary heart disease with pravastatin in men with hypercholesterolemia. West of Scotland Coronary Prevention Study Group. $N$ Engl J Med. 1995;333(20):1301-1307.

35. Randomised trial of cholesterol lowering in 4444 patients with coronary heart disease: the Scandinavian Simvastatin Survival Study (4S). Lancet. 1994;344(8934):1383-1389.

36. Whitney EJ, Krasuski RA, Personius BE, et al. A randomized trial of a strategy for increasing high-density lipoprotein cholesterol levels: effects on progression of coronary heart disease and clinical events. Ann Intern Med. 2005;142(2):95-104.

37. Boden WE, Probstfield JL, Anderson T, et al; AIM-HIGH Investigators. Niacin in patients with low HDL cholesterol levels receiving intensive statin therapy. N Engl J Med. 2011;365(24):2255-2267.

38. Koren MJ, Hunninghake DB; ALLIANCE Investigators. Clinical outcomes in managed-care patients with coronary heart disease treated aggressively in lipid-lowering disease management clinics: the alliance study. J Am Coll Cardiol. 2004;44(9):1772-1779.

39. de Lemos JA, Blazing MA, Wiviott SD, et al; Investigators. Early intensive vs a delayed conservative simvastatin strategy in patients with acute coronary syndromes: phase $\mathrm{Z}$ of the $\mathrm{A}$ to $\mathrm{Z}$ trial. JAMA. 2004;292(11):1307-1316.

40. Ericsson CG, Hamsten A, Nilsson J, Grip L, Svane B, de Faire U. Angiographic assessment of effects of bezafibrate on progression of coronary artery disease in young male postinfarction patients. Lancet. 1996;347(9005):849-853.

41. Goldenberg I, Benderly M, Goldbourt U; BIP Study Group. Secondary prevention with bezafibrate therapy for the treatment of dyslipidemia: an extended follow-up of the BIP trial. J Am Coll Cardiol. 2008;51(4): 459-465.
42. Sacks FM, Pfeffer MA, Moye LA, et al. The effect of pravastatin on coronary events after myocardial infarction in patients with average cholesterol levels. Cholesterol and Recurrent Events Trial investigators. N Engl J Med. 1996;335(14):1001-1009.

43. Results of the low-dose $(20 \mathrm{mg})$ pravastatin GISSI Prevenzione trial in 4271 patients with recent myocardial infarction: do stopped trials contribute to overall knowledge? GISSI Prevenzione Investigators (Gruppo Italiano per lo Studio della Sopravvivenza nell'Infarto Miocardico). Ital Heart J. 2000;1(12):810-820.

44. Athyros VG, Mikhailidis DP, Papageorgiou AA, et al; GREACE Collaborative Group. Effect of atorvastatin on high density lipoprotein cholesterol and its relationship with coronary events: a subgroup analysis of the GREek Atorvastatin and Coronary-heart-disease Evaluation (GREACE) Study. Curr Med Res Opin. 2004;20(5):627-637.

45. Brown BG, Zhao XQ, Chait A, et al. Simvastatin and niacin, antioxidant vitamins, or the combination for the prevention of coronary disease. N Engl J Med. 2001;345(22):1583-1592.

46. Hulley S, Grady D, Bush T, et al. Randomized trial of estrogen plus progestin for secondary prevention of coronary heart disease in postmenopausal women. Heart and Estrogen/progestin Replacement Study (HERS) Research Group. JAMA. 1998;280(7):605-613.

47. Frick MH, Heinonen OP, Huttunen JK, Koskinen P, Mänttäri M, Manninen V. Efficacy of gemfibrozil in dyslipidaemic subjects with suspected heart disease. An ancillary study in the Helsinki Heart Study frame population. Ann Med. 1993;25(1):41-45.

48. Pedersen TR, Faergeman O, Kastelein JJ, et al; Incremental Decrease in End Points Through Aggressive Lipid Lowering (IDEAL) Study Group. High-dose atorvastatin vs usual-dose simvastatin for secondary prevention after myocardial infarction: the IDEAL study: a randomized controlled trial. JAMA. 2005;294(19):2437-2445.

49. Prevention of cardiovascular events and death with pravastatin in patients with coronary heart disease and a broad range of initial cholesterol levels. The Long-Term Intervention with Pravastatin in Ischaemic Disease (LIPID) Study Group. N Engl J Med. 1998;339(19):1349-1357.

50. Schwartz GG, Olsson AG, Ezekowitz MD, et al; Myocardial Ischemia Reduction with Aggressive Cholesterol Lowering (MIRACL) Study Investigators. Effects of atorvastatin on early recurrent ischemic events in acute coronary syndromes: the MIRACL study: a randomized controlled trial. JAMA. 2001;285(13):1711-1718

51. The effect of aggressive lowering of low-density lipoprotein cholesterol levels and low-dose anticoagulation on obstructive changes in saphenous-vein coronary-artery bypass grafts. The Post Coronary Artery Bypass Graft Trial Investigators. N Engl J Med. 1997;336(3): $153-162$.

52. Pitt B, Mancini GB, Ellis SG, Rosman HS, Park JS, McGovern ME. Pravastatin limitation of atherosclerosis in the coronary arteries (PLAC I): reduction in atherosclerosis progression and clinical events. PLAC I investigation. J Am Coll Cardiol. 1995;26(5):1133-1139.

53. Jukema JW, Bruschke AV, van Boven AJ, et al. Effects of lipid lowering by pravastatin on progression and regression of coronary artery disease in symptomatic men with normal to moderately elevated serum cholesterol levels. The Regression Growth Evaluation Statin Study (REGRESS). Circulation. 1995;91(10):2528-2540.

54. LaRosa JC, Grundy SM, Waters DD, et al; Treating to New Targets (TNT) Investigators. Intensive lipid lowering with atorvastatin in patients with stable coronary disease. $N$ Engl J Med. 2005;352(14):1425-1435.

55. Rubins HB, Robins SJ, Collins D, et al. Gemfibrozil for the secondary prevention of coronary heart disease in men with low levels of high-density lipoprotein cholesterol. Veterans Affairs High-Density Lipoprotein Cholesterol Intervention Trial Study Group. NEngl J Med. 1999;341(6):410-418.

56. Morrison A, Hokanson JE. The independent relationship between triglycerides and coronary heart disease. Vasc Health Risk Manag 2009;5(1):89-95. 
57. Miller M, Stone NJ, Ballantyne C, et al; American Heart Association Clinical Lipidology, Thrombosis, and Prevention Committee of the Council on Nutrition, Physical Activity, and Metabolism; Council on Arteriosclerosis, Thrombosis and Vascular Biology; Council on Cardiovascular Nursing; Council on the Kidney in Cardiovascular Disease. Triglycerides and cardiovascular disease: a scientific statement from the American Heart Association. Circulation. 2011;123(20):2292-2333.

58. Law MR, Wald NJ, Rudnicka AR. Quantifying effect of statins on low density lipoprotein cholesterol, ischaemic heart disease, and stroke: systematic review and meta-analysis. BMJ. 2003;326(7404):1423.

59. Davidson MH, McKenney JM, Shear CL, Revkin JH. Efficacy and safety of torcetrapib, a novel cholesteryl ester transfer protein inhibitor, in individuals with below-average high-density lipoprotein cholesterol levels. J Am Coll Cardiol. 2006;48(9):1774-1781.

60. Bays HE, McKenney JM, Dujovne CA, et al; Gemcabene Study Group. Effectiveness and tolerability of a new lipid-altering agent, gemcabene, in patients with low levels of high-density lipoprotein cholesterol. Am J Cardiol. 2003;92(5):538-543.

61. Wittrup HH, Tybjaerg-Hansen A, Nordestgaard BG. Lipoprotein lipase mutations, plasma lipids and lipoproteins, and risk of ischemic heart disease. A meta-analysis. Circulation. 1999;99(22):2901-2907.

62. Hokanson JE. Functional variants in the lipoprotein lipase gene and risk cardiovascular disease. Curr Opin Lipidol. 1999;10(5):393-399.

63. Gagné SE, Larson MG, Pimstone SN, et al. A common truncation variant of lipoprotein lipase (Ser447X) confers protection against coronary heart disease: the Framingham Offspring Study. Clin Genet. $1999 ; 55(6): 450-454$.
64. Hu Y, Liu W, Huang R, Zhang X. A systematic review and metaanalysis of the relationship between lipoprotein lipase Asn291Ser variant and diseases. J Lipid Res. 2006;47(9):1908-1914.

65. Thompson A, Di Angelantonio E, Sarwar N, et al. Association of cholesteryl ester transfer protein genotypes with CETP mass and activity, lipid levels, and coronary risk. JAMA. 2008;299(23):2777-2788.

66. Sarwar N, Sandhu MS, Ricketts SL, et al; Triglyceride Coronary Disease Genetics Consortium and Emerging Risk Factors Collaboration. Triglyceride-mediated pathways and coronary disease: collaborative analysis of 101 studies. Lancet. 2010;375(9726):1634-1639.

67. Frikke-Schmidt R, Nordestgaard BG, Stene MC, et al. Association of loss-of-function mutations in the ABCA1 gene with high-density lipoprotein cholesterol levels and risk of ischemic heart disease. JAMA. 2008;299(21):2524-2532.

68. Di Angelantonio E, Sarwar N, Perry P, et al; Emerging Risk Factors Collaboration. Major lipids, apolipoproteins, and risk of vascular disease. JAMA. 2009;302(18):1993-2000.

69. Sarwar N, Danesh J, Eiriksdottir G, et al. Triglycerides and the risk of coronary heart disease: 10,158 incident cases among 262,525 participants in 29 Western prospective studies. Circulation. 2007;115(4): $450-458$. 


\section{Supplementary material}

Table SI Clinical trials included in the analysis

\begin{tabular}{|c|c|c|c|c|c|}
\hline Study acronym & Cardiovascular outcome & Timepoint (years) $^{a}$ & Treatment arm & N subjects & $\mathbf{N}$ events \\
\hline \multicolumn{6}{|l|}{ Primary prevention ${ }^{\mathrm{b}}$} \\
\hline \multirow[t]{2}{*}{ AFCAPS/TexCAPS ${ }^{28}$} & Fatal/non-fatal MI, unstable & 1 & Placebo & 3,301 & 183 \\
\hline & angina, cardiac death & & Lovastatin & 3,304 & 116 \\
\hline \multirow[t]{2}{*}{ ALLHAT-LLT ${ }^{18}$} & Coronary death or $\mathrm{MI}$ & 2 & Usual care & 5,185 & 421 \\
\hline & & & Pravastatin & 5,170 & 380 \\
\hline \multirow[t]{2}{*}{ ASCOT-LLA ${ }^{29}$} & Coronary death or MI & 2 & Placebo & 5,137 & 154 \\
\hline & & & Atorvastatin & 5,168 & 100 \\
\hline \multirow[t]{2}{*}{ ENHANCE ${ }^{20}$} & Coronary death, MI, stroke, & 2 & Simvastatin & 363 & 7 \\
\hline & revascularization & & Simvastatin/ezetimibe & 357 & 10 \\
\hline \multirow[t]{2}{*}{$\mathrm{HHS}^{30}$} & Coronary death or $\mathrm{Ml}$ & 3 & Placebo & 2,035 & 84 \\
\hline & & & Gemfibrozil & 2,046 & 56 \\
\hline \multirow[t]{2}{*}{ JUPITER ${ }^{31}$} & $\mathrm{CV}$ death, MI, stroke, angina, & 4 & Placebo & 8,901 & 251 \\
\hline & revascularization & & Rosuvastatin & 8,901 & 142 \\
\hline \multirow[t]{2}{*}{ LRC-CPPT ${ }^{9}$} & Coronary death or MI & 7.4 & Placebo & 1,900 & 187 \\
\hline & & & Cholestyramine & 1,906 & 155 \\
\hline \multirow[t]{2}{*}{ MEGA $^{33}$} & Coronary death, Ml, angina, & 5.3-year mean & Diet & 3,966 & 101 \\
\hline & revascularization & & Diet/pravastatin & 3,866 & 66 \\
\hline \multirow[t]{2}{*}{ METEOR $^{32}$} & MI, angina, coronary syndromes & 2-year mean & Placebo & 252 & 0 \\
\hline & & & Rosuvastatin & 624 & 6 \\
\hline \multirow[t]{2}{*}{ SPARCL ${ }^{19}$} & Coronary death or MI & 5-year mean & Placebo & 2,366 & 121 \\
\hline & & & Atorvastatin & 2,365 & 83 \\
\hline \multirow[t]{2}{*}{ WOSCOPS 34} & Coronary death or $\mathrm{MI}$ & 5 & Placebo & 3,293 & 248 \\
\hline & & & Pravastatin & 3,302 & 174 \\
\hline \multicolumn{6}{|l|}{ Secondary prevention ${ }^{c}$} \\
\hline \multirow[t]{2}{*}{$4 S^{35}$} & Coronary death or $\mathrm{Ml}$ & 5.4 & Placebo & 2,223 & 622 \\
\hline & & & Simvastatin & 2,221 & 431 \\
\hline \multirow[t]{2}{*}{ AFREGS $^{36}$} & Coronary death or & 0.96 & Placebo & 72 & 16 \\
\hline & hospitalization for angina & & $\begin{array}{l}\text { Niacin/gemfibrozil/ } \\
\text { cholestyramine }\end{array}$ & 71 & 7 \\
\hline \multirow[t]{2}{*}{ AIM-HIGH ${ }^{37}$} & Coronary death, MI, & 3.0 & Placebo/simvastatin & 1,696 & 274 \\
\hline & revascularization & & Niacin/simvastatin & I,7।8 & 282 \\
\hline \multirow[t]{2}{*}{ ALLIANCE ${ }^{38}$} & Coronary death, Ml, angina, & 4.6 & Usual care & 1,225 & 333 \\
\hline & revascularization & & Atorvastatin & 1,217 & 289 \\
\hline \multirow[t]{2}{*}{$A-Z^{39}$} & Cardiovascular death, MI, & 0.67 & Placebo/simvastatin $20 \mathrm{mg}$ & 2,232 & 343 \\
\hline & readmission ACS, stroke & & Simvastatin $40 / 80 \mathrm{mg}$ & 2,265 & 309 \\
\hline \multirow[t]{2}{*}{ BECAIT $^{40}$} & Coronary death or $\mathrm{MI}$ & 5 & Placebo & 39 & 3 \\
\hline & & & Bezafibrate & 42 & 3 \\
\hline$B I P^{41}$ & Fatal/non-fatal MI or & 6.2 & Placebo & I,542 & 232 \\
\hline & sudden death & & Bezafibrate & $\mathrm{I}, 548$ & 211 \\
\hline CARDS $^{21}$ & Fatal/non-fatal MI & 2 & Placebo & 1,410 & 61 \\
\hline & & & Atorvastatin & 1,428 & 33 \\
\hline CARE $^{42}$ & Coronary death or $\mathrm{MI}$ & 5-year mean & Placebo & 2,078 & 274 \\
\hline & & & Pravastatin & 2,08 I & 212 \\
\hline FIELD 22 & Coronary death or MI & 5 & Placebo & 4,900 & 288 \\
\hline & & & Fenofibrate & 4,895 & 256 \\
\hline GISSI-P43 & Coronary death or MI & 2-year median & Usual care & 2,133 & 83 \\
\hline & & & Pravastatin & 2,138 & 67 \\
\hline GREACE $^{44}$ & Coronary death, MI, & 3-year mean & Usual care & 800 & 196 \\
\hline & angina, revascularization & & Atorvastatin & 800 & 96 \\
\hline HATS $^{45}$ & Coronary death or $\mathrm{Ml}$ & 3.0 & Placebo & 38 & 9 \\
\hline & & & Simvastatin/niacin & 38 & I \\
\hline HERS $^{46}$ & Coronary death or MI & I & Placebo & I,383 & 176 \\
\hline & & & Estrogen-progestin & $\mathrm{I}, 380$ & 172 \\
\hline HHS ancillary ${ }^{47}$ & Coronary death or $\mathrm{MI}$ & 5-year mean & Placebo & 317 & 24 \\
\hline & & & Gemfibrozil & 311 & 35 \\
\hline
\end{tabular}


Table SI (Continued)

\begin{tabular}{|c|c|c|c|c|c|}
\hline Study acronym & Cardiovascular outcome & Timepoint (years) ${ }^{a}$ & Treatment arm & N subjects & $\mathbf{N}$ events \\
\hline \multirow[t]{2}{*}{ IDEAL 48} & Coronary death or MI & 2 & Simvastatin & 4,449 & 463 \\
\hline & & & Atorvastatin & 4,439 & 411 \\
\hline \multirow[t]{2}{*}{ LIPID ${ }^{49}$} & Coronary death or MI & 5-year median & Placebo & 4,502 & 715 \\
\hline & & & Pravastatin & $4,5 \mid 2$ & 557 \\
\hline \multirow[t]{2}{*}{$\mathrm{MIRACL}^{50}$} & Coronary death or MI & 0.31 & Placebo & $\mathrm{I}, 548$ & 169 \\
\hline & & & Atorvastatin & $\mathrm{I}, 538$ & 155 \\
\hline \multirow[t]{2}{*}{ ORIGIN ${ }^{23}$} & Cardiovascular death & 6.2 & Placebo & 6,255 & 581 \\
\hline & & & Omega-3 fatty acids & 6,281 & 574 \\
\hline \multirow[t]{2}{*}{ PCABGT $^{51}$} & Fatal/non-fatal MI & 4.3 & Lovastatin $5 \mathrm{mg}$ & 675 & 40 \\
\hline & & & Lovastatin $80 \mathrm{mg}$ & 676 & 35 \\
\hline \multirow[t]{2}{*}{ PLAC-I $\left.\right|^{52}$} & Coronary death or MI & 3 & Placebo & 202 & 19 \\
\hline & & & Pravastatin & 206 & 10 \\
\hline \multirow[t]{2}{*}{ REGRESS $^{53}$} & Coronary death or MI & 1 & Placebo & 434 & 16 \\
\hline & & & Pravastatin & 450 & 9 \\
\hline \multirow[t]{2}{*}{ STARS ${ }^{10}$} & Coronary death or MI & 3.25-year mean & Usual care & 24 & 5 \\
\hline & & & Diet/cholestyramine & 24 & I \\
\hline \multirow[t]{2}{*}{$\mathrm{TNT}^{54}$} & Coronary death or $\mathrm{MI}$ & 3 & Atorvastatin $10 \mathrm{mg}$ & 5,006 & 418 \\
\hline & & & Atorvastatin $80 \mathrm{mg}$ & 4,995 & 334 \\
\hline \multirow[t]{2}{*}{ VA-HIT ${ }^{55}$} & Coronary death or MI & 3 & Placebo & 1,267 & 275 \\
\hline & & & Gemfibrozil & 1,264 & 219 \\
\hline \multicolumn{6}{|c|}{ Mixed primary and secondary prevention ${ }^{d}$} \\
\hline \multirow[t]{2}{*}{$\mathrm{ACCORD}^{24}$} & Nonfatal MI or stroke, & 5 & Simvastatin/placebo & 2,753 & 310 \\
\hline & or $\mathrm{CV}$ death & & Simvastatin/fenofibrate & 2,765 & 291 \\
\hline \multirow[t]{2}{*}{ Holicos-PAT ${ }^{26}$} & Coronary death, MI, & I & Diet only & 749 & 37 \\
\hline & angina, revascularization & & Pravastatin & 1,290 & 58 \\
\hline \multirow[t]{2}{*}{$\mathrm{HPS}^{25}$} & Coronary death or MI & 3 & Placebo & 10,267 & 1212 \\
\hline & & & Simvastatin & 10,269 & 898 \\
\hline \multirow[t]{2}{*}{ PROSPER $^{27}$} & Coronary death or MI & 0.25 & Placebo & 2,913 & 356 \\
\hline & & & Pravastatin & 2,891 & 292 \\
\hline
\end{tabular}

Notes: ${ }^{\text {TT }}$ The timepoint is either a single time at which the lipid values were reported or, if indicated, the time over which the on-study mean or median was calculated; ${ }^{b}$ ALLHAT-LLT had I4\% of subjects with a history of coronary heart disease, but no indication of prior cardiovascular events, so was considered a primary prevention study. Patients in the SPARCL trial had had a stroke, but did not have coronary heart disease. Patients in ENHANCE were at increased risk due to elevated TC, but were primary with respect to cardiovascular events; 'subjects in CARDS and FIELD had diabetes (a CHD risk equivalent), and were therefore classified with the secondary prevention studies. Subjects in ORIGIN were at high CV risk due to a history of CV events or diabetes; ${ }^{\circledR}$ populations were classified as mixed primary and secondary prevention if some subjects had a history cardiovascular events (36.5\% in ACCORD, $41 \%$ in HPS), diabetes (13\%-18\% in Holicos-PAT), or vascular disease (44\% in PROSPER, I7.5\% in Holicos-PAT).

Abbreviations: 4S, Scandinavian Simvastatin Survival Study; ACCORD, Action to Control Cardiovascular Risk in Diabetes; AFCAPS/TexCAPS, Air Force/Texas Coronary Atherosceloris Prevention Study; AFREGS, Armed Forces Regression Study; AIM-HIGH, Atherothrombosis Intervention in Metabolic syndrome with low HDL/High triglycerides: Impact on Global Health outcomes; ALLHAT-LLT, Antihypertensive and Lipid-Lowering Treatment to Prevent Heart Attack Trial; ALLIANCE, Aggressive LipidLowering Initiation Abates New Cardiac Events; ASCOT-LLA, Anglo-Scandinavian Cardiac Outcomes Trial--Lipid Lowering Arm; A-Z, A to Z Trial; BECAIT, BEzafibrate Coronary Atherosclerosis Intervention Trial; BIP, Bezafibrate Infarction Prevention; CARDS, Collaborative Atorvastatin Diabetes Study; CARE, Cholesterol and Recurrent Events; CHD, coronary heart disease; CV, cardiovascular; ENHANCE, Ezetimibe and Simvastatin in Hypercholesterolemia Enhances Atherosclerosis Regression; FIELD, Fenofibrate Intervention and Event Lowering in Diabetes; GISSI-P. Gruppo Italiano per lo Studio della Sopravvivenza nell'Infarto Miocardico-Prevenzione; GREACE, GREek Atorvastatin and Coronary heart disease Evaluation; HATS, HDL Atherosclerosis Treatment Study; HERS, Heart and Estrogen/progestin Replacement Study; HHS, Helsinki Heart Study; Hollicos-PAT, Hokuriku lipid coronary heart disease study-pravastatin atherosclerosis trial; HPS, Heart Protection Study; IDEAL, Incremental Decrease in End points through Aggressive Lipid lowering; JUPITER, Justification for the Use of Statins in Prevention: an InterventionTrial Evaluating Rosuvastatin; LIPID, Long-term Intervention with Pravastatin in Ischaemic Disease; LRC-CPPT, Lipid Research Clinics Coronary Primary Prevention Trial; MEGA, The Management of Elevated Cholesterol in the Primary Prevention Group of Adult Japanese; METEOR, Measuring Effects on Intima-Media Thickness: an Evaluation of Rosuvastatin; MI, myocardial infarction; MIRACL, Myocardial Ischemia Reduction with Aggressive Cholesterol Lowering; NR, not reported; ORIGIN, Outcome Reduction with an Initial Glargine Intervention; PCABGT, Post Coronary Artery Bypass Graft Trial; PLAC-I, Pravastatin Limitation of Atherosclerosis in the Coronary arteries; PROSPER, PROspective Study of Pravastatin in the Elderly at Risk; REGRESS, Regression Growth Evaluation Statin Study; SPARCL, Stroke Prevention by Aggressive Reduction in Cholesterol Levels; STARS, St Thomas' Atherosclerosis Regression Study; TC, total cholesterol; TNT, Treating to New Targets; VA-HIT, Veterans Affairs High-density lipoprotein cholesterol Intervention Trial; WOSCOPS, West of Scotland Coronary Prevention Study.

Vascular Health and Risk Management

\section{Dovepress}

\section{Publish your work in this journal}

Vascular Health and Risk Management is an international, peerreviewed journal of therapeutics and risk management, focusing on concise rapid reporting of clinical studies on the processes involved in the maintenance of vascular health; the monitoring, prevention and treatment of vascular disease and its sequelae; and the involvement of metabolic disorders, particularly diabetes. This journal is indexed on PubMed Central and MedLine. The manuscript management system is completely online and includes a very quick and fair peer-review system, which is all easy to use. Visit http://www.dovepress.com/ testimonials.php to read real quotes from published authors. 